\title{
Quality assessment of DNA derived from up to 30 years old formalin fixed paraffin embedded (FFPE) tissue for PCR-based methylation analysis using SMART-MSP and MS-HRM Lasse S Kristensen ${ }^{1}$, Tomasz K Wojdacz ${ }^{1}$, Britta B Thestrup ${ }^{1}$, Carsten Wiuf2, Henrik Hager ${ }^{3}$ and Lise Lotte Hansen*1
}

Address: ${ }^{1}$ Institute of Human Genetics, University of Aarhus, The Bartholin Building, Wilhelm Meyers Allé 4, DK-8000 Aarhus C, Denmark, ${ }^{2}$ Bioinformatics Research Center (BiRC), C. F. Møllers Alle 8, Building 1110, Aarhus University, 8000 Århus C, Denmark and ${ }^{3}$ Department of Pathology Aarhus University Hospital Norrebrogade 45, DK-8000 Aarhus C, Denmark

Email: Lasse S Kristensen - lasse@humgen.au.dk; Tomasz K Wojdacz - wojdacz@humgen.au.dk; Britta B Thestrup - boserup@humgen.au.dk; Carsten Wiuf - wiuf@birc.au.dk; Henrik Hager - henrikhager@mac.com; Lise Lotte Hansen* - Lotte@ humgen.au.dk

* Corresponding author

Published: 21 December 2009

BMC Cancer 2009, 9:453 doi:10.1 | 86/ |47|-2407-9-453
Received: 30 May 2009

Accepted: 21 December 2009

This article is available from: http://www.biomedcentral.com/I47I-2407/9/453

(c) 2009 Kristensen et al; licensee BioMed Central Ltd.

This is an Open Access article distributed under the terms of the Creative Commons Attribution License (http://creativecommons.org/licenses/by/2.0), which permits unrestricted use, distribution, and reproduction in any medium, provided the original work is properly cited.

\begin{abstract}
Background: The High Resolution Melting (HRM) technology has recently been introduced as a rapid and robust analysis tool for the detection of DNA methylation. The methylation status of multiple tumor suppressor genes may serve as biomarkers for early cancer diagnostics, for prediction of prognosis and for prediction of response to treatment. Therefore, it is important that methodologies for detection of DNA methylation continue to evolve. Sensitive Melting Analysis after Real Time - Methylation Specific PCR (SMART-MSP) and Methylation Sensitive - High Resolution Melting (MS-HRM) are two methods for single locus DNA methylation detection based on HRM.

Methods: Here, we have assessed the quality of DNA extracted from up to 30 years old Formalin Fixed Paraffin Embedded (FFPE) tissue for DNA methylation analysis using SMART-MSP and MS-HRM. The quality assessment was performed on DNA extracted from 54 Non-Small Cell Lung Cancer (NSCLC) samples derived from FFPE tissue, collected over 30 years and grouped into five years intervals. For each sample, the methylation levels of the CDKN2A ( $p / 6)$ and RARB promoters were estimated using SMART-MSP and MS-HRM assays designed to assess the methylation status of the same $C_{P} G$ positions. This allowed for a direct comparison of the methylation levels estimated by the two methods for each sample.

Results: CDKN2A promoter methylation levels were successfully determined by SMART-MSP and MS-HRM in all 54 samples. Identical methylation estimates were obtained by the two methods in 46 of the samples. The methylation levels of the RARB promoter were successfully determined by SMART-MSP in all samples. When using MS-HRM to assess RARB methylation five samples failed to amplify and 15 samples showed a melting profile characteristic for heterogeneous methylation. Twenty-seven of the remaining 34 samples, for which the methylation level could be estimated, gave the same result as observed when using SMART-MSP.

Conclusion: MS-HRM and SMART-MSP can be successfully used for single locus methylation studies using DNA derived from up to 30 years old FFPE tissue. Furthermore, it can be expected that MS-HRM and SMART-MSP will provide similar methylation estimates when assays are designed to analyze the same $C_{p} G$ positions.
\end{abstract}




\section{Background}

More than two decades of research have identified DNA methylation of the carbon-5 position of cytosine residues followed by guanine ( $\mathrm{CpG}$ dinucleotides) as a very important epigenetic mechanism involved in the development of human cancer. Numerous tumor suppressor genes undergo de novo methylation and silencing in various cancers despite an overall reduced methylation content of the cancer genome. These changes have shown to be widely implicated in the development and progression of human cancers [1]. Furthermore, the aberrant methylation events take place early in tumorigenesis, and may therefore be used as a potential biomarker for early cancer detection [2].

A sufficient number of clinical samples of high DNA quality are often unavailable for retrospective studies involving DNA methylation biomarkers and studies of other clinically important questions relating to DNA methylation. On the other hand, DNA samples from Formalin Fixed Paraffin Embedded (FFPE) tissue are often abundant and have been stored for decades. However, the use of DNA from old FFPE tissue may be problematic as the DNA is often degraded and only limited amounts may be available. Furthermore, sodium bisulfite treatment [3], preserving methylation marks, and as such necessary for PCR-based studies of DNA methylation, may further degrade the DNA.

Many different PCR-based methods for the detection of DNA methylation have been developed [4]. Methylation specific PCR (MSP) [5] is the most widely used as it is very sensitive, cost-effective, and does not require specialized equipment. However, MSP has several drawbacks. First, it is a non-quantitative method. Measurement of the methylation level in a sample may be relevant, since low-level methylation may not be associated with transcriptional silencing [6]. Second, MSP is prone to false-positive results [7-9]. Third, MSP is not a closed-tube method, which increases the risk of PCR contamination. In a technique called MethyLight [10], the use of TaqMan probes located in between the MSP primers allow for methylation levels to be estimated. This, however, increases the costs of the experiments.

The second range of PCR-based methods, used in locus specific methylation studies, amplifies the DNA template regardless of its methylation status, which can be analyzed post-PCR by a variety of different platforms [3,11-14]. However, it is often difficult to achieve a methylationindependent PCR amplification due to the PCR bias phenomenon, which is described as preferential amplification of unmethylated templates $[15,16]$.

In collaboration with A. Dobrovic and colleagues, we have recently developed two methods for the analysis of
DNA methylation aiming at overcoming some of the problems of previously described methodologies. Both methods utilize the High-Resolution Melting (HRM) technology [17]. The first, Methylation-Sensitive HRM (MS-HRM) $[18,19]$, relies on primers designed to amplify the target independent of its methylation status. The second, Sensitive Melting Analysis after Real Time - Methylation Specific PCR (SMART-MSP) [7], utilizes primers designed to amplify only methylated templates as is the case for MSP and MethyLight. SMART-MSP allows quantifying methylation levels in a cost-effective manner, by using intercalation dyes instead of fluorescent probes. Furthermore, SMART-MSP allows some false-positive results to be excluded from the experiments via HRM analysis, which is an integral part of the protocol [7]. Both methods have shown to be highly sensitive, and allow estimation of the methylation levels in the samples $[7,18]$. Estimation of methylation levels in MS-HRM is performed on the basis of a comparison of melting profiles of screened samples and standards of known ratios of methylated and unmethylated DNA, whereas in SMART-MSP the real-time PCR data are used to quantify methylation levels. The main feature of MS-HRM, as described by Wojdacz and Dobrovic [20], is that it allows controlling of the PCR bias during methylation-independent PCR amplification. This is achieved by including a limited number of CpG sites in the primers and optimizing the annealing temperature $[16,20]$. The same real-time PCR and HRM instrument and reagents are used for both methods facilitating independent result verifications.

We have assessed the quality of DNA extracted from archival Non-Small Cell Lung Cancer (NSCLC) FFPE tissue for DNA methylation analysis using the SMART-MSP and MSHRM methodologies. SMART-MSP and MS-HRM assays were designed to analyze the same CpG positions to allow a direct comparison of the methylation level of the samples, dating 5 - 30 years back in time. The methylation status of the CDKN2A (p16) and RARB promoter CpG islands were analyzed. Variation amongst replicates and amongst bisulfite modifications was evaluated. Furthermore, immunohistochemical staining for the $\mathrm{p} 16$ protein was performed and correlated to the methylation status of the samples.

\section{Methods}

\section{Samples and DNA Extraction}

FFPE blocks from 54 Non-Small Cell Lung Cancer (NSCLC) patients were selected from the archives of the Institute of Pathology, Aarhus University Hospital. Seven samples were 30 years old, eight samples were 25 years old, 13 samples were 20 years old, 10 samples were 15 years old, 10 samples were 10 years old, and six samples were five years old. Blocks containing large areas of carcinoma infiltration were selected. For each sample, four tissue sections of $10 \mu \mathrm{m}$ were transferred into a 
microcentrifuge tube and incubated in $1.5 \mathrm{ml}$ of xylene for $30 \mathrm{~min}$ at $37^{\circ} \mathrm{C}$. After centrifugation at $14,000 \mathrm{rpm}$ for 3 min, the supernatant was removed. This step was repeated once. Subsequently, the tissue samples were washed in $1 \mathrm{ml}$ of $99 \%$ ethanol. After centrifugation at $7200 \mathrm{rpm}$ for $3 \mathrm{~min}$ the supernatant was discharged. The washing procedure was repeated twice. The samples were air dried at ambient temperature for $30 \mathrm{~min}$. DNA was extracted using the MagNA Pure LC (Roche Molecular Biochemicals, Penzberg/Germany), a semi-automatic system for isolation of nucleic acids utilizing magnetic bead technology. The purification was done according to the manufacture's instructions.

DNA was extracted from peripheral blood (PB) obtained from medical students of both sexes in their first year at Medical school, following a modified salt precipitation protocol as previously described [21].

The Local Ethical Committee, Aarhus County, Denmark, approved this study.

\section{Stereological analysis}

In order to estimate the amount of tumor tissue and necrosis in the sections and to detect if low level of methylation were due to low amount of vital tumor, we chose to determine the area fraction (AF) of these two components. The stereological analysis was performed using a light microscope equipped with a computer assisted stereology system (CAST, Olympus, Denmark). The counting frame covered an area of $8,320 \mu \mathrm{m}$ and the sampling was done in a systematic, random fashion. A median number of 18 (range 5-26) and 20 (range 4-40) counting frames were evaluated for vital tumor and necrosis, respectively. The AF staining positive for vital tumor and necrosis was determined by point-counting [22] at a magnification of $\times 739$. Points hitting artifacts were not considered.

\section{Preparation of control samples}

Universal methylated DNA (Chemicon, Millipore, Billerica, MA) was subjected to bisulfite modification as described below and used as a methylation positive control for the SMART-MSP and MS-HRM assays. DNA extracted from PB was subjected to whole genome amplification (WGA) for creation of an unmethylated control. The WGA was performed as previously described [7], in which the primary WGA product was subjected to a second round of WGA. The secondary WGA product was subjected to bisulfite modification, as described below, and used as an unmethylated control. A standard dilution series, of $100 \%, 10 \%, 1 \%$, and $0.1 \%$ methylated DNA in a background of unmethylated DNA, was prepared by serially diluting the methylation positive control into the unmethylated control. These standards were used for assessing the sensitivity of the SMART-MSP and MS-HRM assays, and for melting profile comparisons with the samples in MS-HRM. For the SMART-MSP assays the standard dilution series were, in addition, used to assess the quantitative accuracy and the PCR efficiency of the assays using the LightCycler 480 Software Version 1.5.

\section{Sodium Bisulfite Treatment}

Five hundred nanograms of genomic DNA was subjected to sodium bisulfite treatment with the EpiTect ${ }^{\circledR}$ Bisulfite kit (Qiagen, Hilden, Germany) according to the manufacturer's instructions.

\section{MS-HRM and SMART-MSP primer design}

MS-HRM primers were designed to be methylation independent according to the guidelines given in [20], and the SMART-MSP primers were designed to be methylation specific according to the guidelines given in [7]. The SMART-MSP assays were designed to assess the same CpG positions as the MS-HRM assays (Figure 1) to allow for a direct comparison of the methylation levels estimated by the two methods. For this reason, it was not possible to include CPG sites between the SMART-MSP primers to allow for the detection of false positive results due to false priming events as described [7]. Both SMART-MSP assays have one non-CpG cytosine between the primers. The conversion status of these cytosines can be assessed by the HRM analysis, and a right-shifted melting profile indicate that the observed amplification may be due to incomplete conversion of unmethylated cytosines [7]. The primer sequences and genomic regions spanned, as well as amplicon sizes and the annealing temperatures $\left(\mathrm{T}_{\mathrm{A}}\right)$ are listed in Table 1.

\section{SMART MSP control assay}

In SMART-MSP a control assay was used to normalize for DNA input in the reactions as DNA concentrations cannot be measured directly after bisulfite modification. We have used a control assay based on Alu sequences depleted of CpG sites by evolutionary deamination previously described [23]. This assay is less susceptible to normalization errors caused by aneuploidy and copy number changes often observed in cancer cells, and is especially suitable for determining relative DNA amounts in samples where the quantity and/or quality may be limited [23]. Here, this assay was successfully applied for SMARTMSP quantification without the TaqMan probe using an intercalating fluorescent dye instead.

\section{$P C R$ and HRM Conditions}

PCR cycling and HRM analysis were performed on the LightCycler $^{\circledast} 480$ (Roche Applied Science, Mannheim, Germany). The reaction mixtures consisted of $20 \mathrm{ng}$ of bisulfite modified DNA using the LC480 HRM Scanning Master (Roche) with primer concentrations of $200 \mathrm{nmol} /$ $\mathrm{l}$ of each primer and a final $\mathrm{MgCl}_{2}$ concentration of 3 


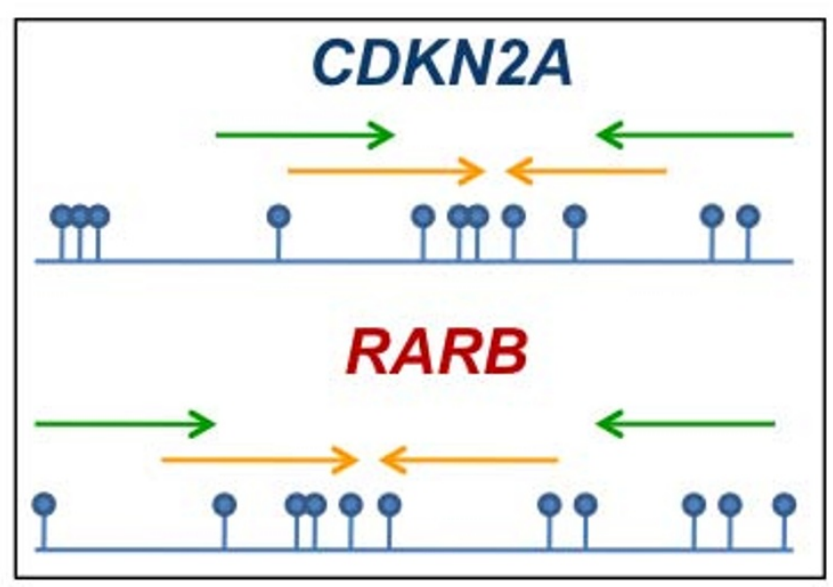

Figure I

The design of the CDKN2A and RARB SMART-MSP and MS-HRM assays. The SMART-MSP assays were designed to analyze the same CPG positions as the MS-HRM assays to allow for a direct comparison of the methylation levels in the samples. The MS-HRM primers are denoted as green arrows and the SMART-MSP primers as orange arrows. The $C_{p} G$ positions are denoted as lollipops.

$\mathrm{mmol} / \mathrm{l}$ in a total volume of $10 \mu \mathrm{l}$. The cycling protocol started with one cycle of $95^{\circ} \mathrm{C}$ for 10 minutes for enzyme activation followed by 45 cycles of $95^{\circ} \mathrm{C}$ for 5 seconds, $\mathrm{T}_{\mathrm{A}}$ (Table 1) for 10 seconds, $72^{\circ} \mathrm{C}$ for 10 seconds, one cycle of $95^{\circ} \mathrm{C}$ for 1 minute, one cycle of $65^{\circ} \mathrm{C}$ for 1 minute and a melt from 65 to $95^{\circ} \mathrm{C}$ for all assays. In the ALU control assay the PCR cycling steps was performed for 10, 20, 20 seconds instead of 5,10,10 seconds. The melting step was performed using 30 acquisitions per ${ }^{\circ} \mathrm{C}$. For the MS-HRM assays the annealing temperatures were experimentally determined for each assay to ensure that the $0.1 \%$ methylated standard could be detected. For the SMART-MSP assays the annealing temperatures were experimentally determined for each assay to ensure that only methylated templates were amplified. All samples were analyzed in triplicate.

\section{MS-HRM and SMART-MSP data analysis}

In MS-HRM, the methylation levels of each sample were assessed by comparison of the PCR product melting profiles between each sample and the standards with known ratio of methylated and unmethylated templates as described [18]. Here, the melting profiles of samples were compared to melting profiles of PCR products derived from mixes of $100 \%, 10 \%, 1 \%, 0.1 \%$ and $0 \%$ of fully methylated template in an unmethylated background, and scored as being methylated at low level (0.1-1\%) medium level (1-10\%) or high level (10-100\%). The samples were scored as being heterogeneously methylated if a melting profile characteristic for the amplification of molecules of different methylation content was observed as previously described $[13,24]$.

In SMART-MSP, the relative methylation levels in the samples were estimated relative to universal methylated DNA (Chemicon) using the $2^{-\Delta \Delta \mathrm{Ct}}$ real-time PCR quantification approach ()[25], as described in [7] in which $\Delta \Delta \mathrm{Ct}=$ unknown sample $\left(\mathrm{Ct}_{\text {target gene }}-\mathrm{Ct}_{\mathrm{ALU} \text { control }}\right)-100 \%$ methylated DNA $\left(\mathrm{Ct}_{\text {target gene }}-\mathrm{Ct}_{\mathrm{ALU}}\right.$ control $)$. This approach implies that the methylation assays have approximately the same $E$ as the control assay ()[25]. The HRM profiles of the samples were compared to the melting profile of universal methylated DNA (Chemicon) and results were discarded if a deviation of more than $0.5 \Delta \mathrm{C}$ was observed. The melting temperature of each assay was approximately $80.3^{\circ} \mathrm{C}$ for CDKN2A and $77.4^{\circ} \mathrm{C}$ for RARB.

The samples were analyzed in triplicates in order to assess if the reproducibility amongst replicates of the SMARTMSP assays decreased with the age of the samples. For this purpose, three different methylation estimates were calculated from the individual Ct-values of the triplicates of each sample in the control assay and the respective methylation assay. The first value is the lowest possible methylation estimate that can be calculated from the Ct-values (using the highest Ct-value of the methylation assay and the lowest Ct-value of the control assay of the triplicates). The second value is calculated from the average Ct-value of the triplicates, whereas the third value is the highest possible value that can be calculated from the Ct-values (using the lowest Ct-value of the methylation assay and the highest Ct-value of the control assay).

In MS-HRM, at least two of the three replicates of a sample need to give the same result (methylation positive or methylation negative) for the methylation level to be determined. For both methods, samples were scored as "failed amplification" when only one or none of the three replicates amplified.

\section{The sensitivity and quantitative accuracy of the assays}

A standard dilution series from $100 \%$ to $0.1 \%$ methylated DNA was used to assess the sensitivity of the CDKN2A and RARB SMART-MSP and MS-HRM assays (Figure 2).

In addition, the standard dilution series was used for the SMART-MSP assays to assess the quantitative accuracy and the PCR efficiency of each assay.

Based on the standard curve the LC480 software measures an Error value (mean squared error of the single data points fit to the regression line). The Error value is a measurement of the quantitative accuracy of the assays. An 
Table I: Primer sequences, annealing temperatures, and amplicon information for the MS-HRM and SMART-MSP assays (UCSC Genome Browser, August 2008).

\begin{tabular}{|c|c|c|c|c|c|}
\hline Gene & $\begin{array}{l}\text { Primer sequences (CpG sites } \\
\text { underlined and converted Cs as } \\
\text { capital Ts or } A s) .\left(5^{\prime} \rightarrow 3^{\prime}\right) \text {. }\end{array}$ & $\begin{array}{l}\text { Annealing } \\
\text { temperature }\end{array}$ & Amplicon size & $\begin{array}{l}\text { CpGs/non-CpG-Cs } \\
\text { between the primers }\end{array}$ & $\begin{array}{l}\text { Spanned } \\
\text { region(bp) }\end{array}$ \\
\hline $\begin{array}{l}\text { CDKN2A } \\
\text { (MS-HRM) }\end{array}$ & $\begin{array}{l}\text { F-ggagTTttcggTtgaTtggTtggTT } \\
\text { R-aAcaAcgcccgcacctcctcta }\end{array}$ & $64^{\circ} \mathrm{C}$ & $69 \mathrm{bp}$ & $5 / 3$ & $\begin{array}{l}21964733-21964800 \\
\text { of Chr. } 9\end{array}$ \\
\hline $\begin{array}{c}\text { RARB } \\
\text { (MS-HRM) }\end{array}$ & $\begin{array}{l}\text { F-cgagT tgtttgagga TtgggatgT } \\
\text { R-aatAcgttccgAatcctacccc }\end{array}$ & $64^{\circ} \mathrm{C}$ & 89 bp & $7 / 5$ & $\begin{array}{l}25444840-25444928 \\
\text { of Chr. } 3\end{array}$ \\
\hline $\begin{array}{c}\text { CDKN2A } \\
\text { (SMART-MSP) }\end{array}$ & $\begin{array}{l}\text { F-gTtgaTtggTtggTTacgTcgc } \\
\text { R-ctcctctacccgaccccgA }\end{array}$ & $64^{\circ} \mathrm{C}$ & $45 \mathrm{bp}$ & $0 / 1$ & $\begin{array}{l}21964746-21964790 \\
\text { of Chr. } 9\end{array}$ \\
\hline $\begin{array}{c}\text { RARB } \\
\text { (SMART-MSP) }\end{array}$ & $\begin{array}{l}\text { F-gggatgTcgagaacgcgagc } \\
\text { R-cgAtAcccaAacaaaccctActcg }\end{array}$ & $64^{\circ} \mathrm{C}$ & $48 \mathrm{bp}$ & $0 / 1$ & $\begin{array}{l}25444857-25444904 \\
\text { of Chr. } 3\end{array}$ \\
\hline $\begin{array}{l}\text { ALU control } \\
\text { (SMART-MSP) }\end{array}$ & $\begin{array}{l}\text { F-ggttaggtatagtggtttatatttgtaattttagta } \\
\text { R-attaactaaactaatcttaaactcctaacctca }\end{array}$ & $62^{\circ} \mathrm{C}$ & $98 \mathrm{bp}$ & $N / A$ & $\begin{array}{l}\text { Consensus seq., See } \\
\text { ref [23]. }\end{array}$ \\
\hline
\end{tabular}

acceptable Error value should be less than 0.2 according to the LightCycler 480 Instrument Operator's Manual. The Error value for the CDKN2A assay was 0.13 , the Error value for the RARB assay was 0.10 , and the Error value for the ALU control assay was 0.13 .

The LC480 software was also used to calculate the PCR efficiency $(E)$ from the standard curve for each of the SMART-MSP assays. The $E$ value for each assay was: $C D K N 2 A=2.01, R A R B=2.07$, and ALU Control $=2.02$.

\section{Immunohistochemistry}

Sections of fixed paraffin-embedded tissue were dewaxed in xylene and rehydrated in graded alcohol. Endogenous peroxidase activity was blocked by 0.5 per cent $\mathrm{H}_{2} \mathrm{O}_{2}$ in absolute methanol for $10 \mathrm{~min}$ at room temperature. To reveal antigen, the sections were pretreated by boiling in target reveal solution (DAKO, Denmark) using a microwave oven. Non-specific binding of immunoglobulin was quenched by incubating the sections in 10 per cent goat serum for $20 \mathrm{~min}$. Sections were incubated with a 1:50 diluted mouse-antihuman monoclonal p16 antibody (clone G175-405, monoclonal mouse IgG; Pharmingen, San Diego, CA). Antigen - antibody reaction was detected by incubation with EnVisionTM+ Dual Link System-HRP (DAKO, Denmark). The peroxidase activity was visualized by 0.05 per cent 3,3-diaminobenzidine tetrahydro-chloride (Kem-En-Tek, Denmark) dissolved in PBS containing 0.1 percent $\mathrm{H}_{2} \mathrm{O}_{2}$. Counterstaining was carried out using Mayer's haematoxylin. Finally, the sections were dehydrated in graded alcohol and mounted in hydrophobic mounting media. Negative controls were obtained after incubation of the sections in PBS instead of primary antibodies. Reactive lymphocytes and inflammatory cells served as positive internal controls. A tumor was considered positive if $5 \%$ of the nuclei showed nuclear staining.

\section{Results}

\section{Methylation analysis of the FFPE samples}

The methylation levels of the CDKN2A and RARB promoters in 54 FFPE NSCLC samples, stored between 1978 and 2003, were estimated by the MS-HRM and SMARTMSP assays. The estimates of the methylation levels are given in Table 2. As described in the methods section three different methylation estimates were calculated for each sample when using SMART-MSP to evaluate the variation between replicates. The integrity of the DNA was sufficient for all samples showing 0\% methylation in the SMARTMSP assays, as all of these samples amplified in the ALU control assay.

For CDKN2A we could successfully determine the methylation levels of all 54 samples using both methods. In 46 of the 54 samples the average SMART-MSP methylation estimate (second column within the SMART-MSP column in Table 2) was within the range estimated by MS-HRM. This is unlikely to have occurred by chance (Binomial test, p-value $\left.1.384 \times 10^{-7}\right)$.

Methylation levels for $R A R B$ were successfully determined when using SMART-MSP of all 54 samples. Five samples failed to amplify when using MS-HRM. The MS-HRM results indicated that heterogeneously methylated molecules were amplified in 15 of the samples. An example of a heterogeneously methylated sample is shown in figure 3. All of the heterogeneously methylated samples were estimated to be methylated at low levels (0\%-3.6\%) by SMART-MSP. Twenty-seven of the remaining 34 samples had an average SMART-MSP methylation estimate (second column within the SMART-MSP column in Table 2) within the range estimated by MS-HRM. This is unlikely to have occurred by chance (Binomial test, p-value $0.0008214)$. 


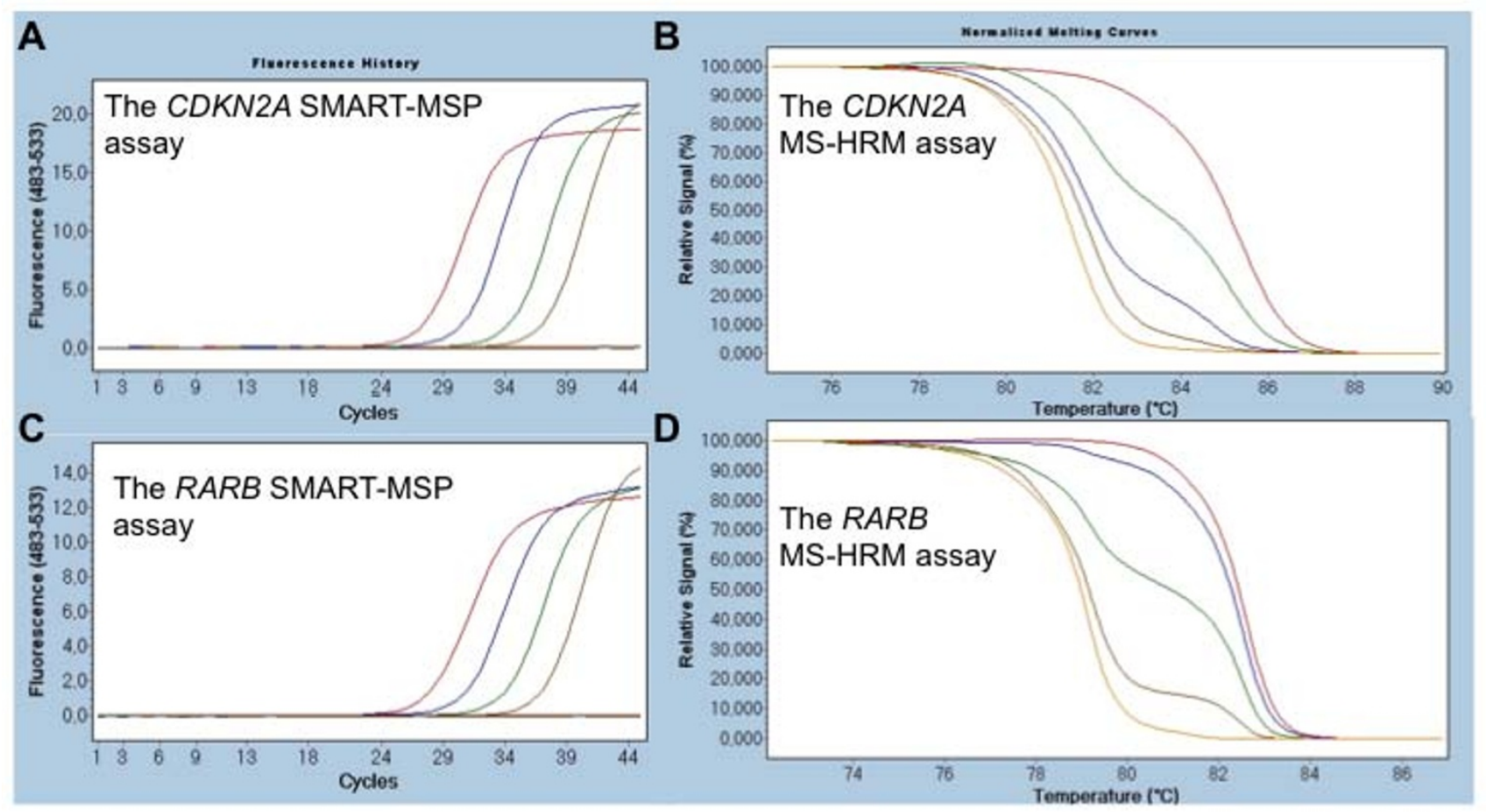

Figure 2

The sensitivity of the CDKN2A and RARB SMART-MSP and MS-HRM assays. The sensitivity of the assays was tested using standard dilution series of methylated DNA into unmethylated DNA. The $100 \%$ methylated standards are indicated in red, the $10 \%$ methylated standards in blue, the $1 \%$ methylated standards in green, the $0.1 \%$ methylated standards in brown, the $0 \%$ methylated standard in orange and non template controls are indicated in black. $\mathbf{A}$. The CDKN2A SMART-MSP assay (realtime amplification data). B. The CDKN2A MS-HRM assay (normalized melting curves). C. The RARB SMART-MSP assay (realtime amplification data). D. The RARB MS-HRM assay (normalized melting curves). All assays successfully detect $0.1 \%$ methylation.

To evaluate if the reproducibility of the methylation estimates amongst replicates was dependent on the age of the samples, we plotted the absolute difference between the highest and lowest possible methylation estimate divided by the average methylation estimate against the age of the samples for each gene (Figure 4). From these plots, it was concluded that the reproducibility of the SMART-MSP assays did not decrease with the age of the samples. In general, the reproducibility was better for the CDKN2A SMART-MSP assay compared to the RARB SMART-MSP assay.

\section{Percentage of tumor tissue and necrosis versus methylation level}

The amount of tumor tissue and necrosis in the sections were determined in order to evaluate if low level of methylation were due to low amount of vital tumor or influenced by the amount of necrosis. However, we found no difference in area of necrosis or vital tumor between the tumors with low, medium or high level of methylation (data not shown). This may be due to the fact that meth- ylation of both CDKN2A and RARB can be detected in adjacent normal lung tissue [26].

\section{Immunohistochemistry}

It is well known that the quality of old FFPE samples is sufficient for immunohistochemistry to be performed. Therefore, we evaluated whether the immunohistochemical staining of the p16 protein correlated with methylation status of the CDKN2A (p16) gene. An example of a positive and a negative sample is shown in figure 5 , and the results can be found in table 2. Immunohistochemistry results were available for all samples except two. Eighteen of the 20 methylated samples for which immunohistochemistry results were available were negative. The two methylated samples that were positive by immunohistochemistry were only found to be methylated at very low levels $(0.1 \%-1 \%$ by MS-HRM as well as by SMART-MSP). Of the 30 unmethylated samples for which immunohistochemistry results were available 18 samples were positive. Thus, an association between methylation and immunohistochemical staining was found (Pearson's 
Table 2: Methylation levels of the samples as estimated by MS-HRM and SMART-MSP.

\begin{tabular}{|c|c|c|c|c|c|c|c|c|c|}
\hline \multirow{3}{*}{ Sample } & \multirow{3}{*}{$\begin{array}{l}\text { Immunohistochemistry } \\
\text { for } \mathrm{p} 16\end{array}$} & \multicolumn{4}{|c|}{ Methylation levels estimated for CDKN2A } & \multicolumn{4}{|c|}{ Methylation levels estimated for RARB } \\
\hline & & \multirow[t]{2}{*}{ MS-HRM } & \multicolumn{3}{|c|}{ SMART-MSP } & \multirow[t]{2}{*}{ MS-HRM } & \multicolumn{3}{|c|}{ SMART-MSP } \\
\hline & & & $\begin{array}{l}\text { Lowest } \\
\text { estimate }\end{array}$ & $\begin{array}{l}\text { Average } \\
\text { estimate }\end{array}$ & $\begin{array}{l}\text { Highest } \\
\text { estimate }\end{array}$ & & $\begin{array}{l}\text { Lowest } \\
\text { estimate }\end{array}$ & $\begin{array}{l}\text { Average } \\
\text { estimate }\end{array}$ & $\begin{array}{l}\text { Highest } \\
\text { estimate }\end{array}$ \\
\hline I (1978) & Negative & $0.1 \%-1 \%$ & $1.7 \%$ & $2.7 \%$ & $3.4 \%$ & Failed ampl & $0 \%$ & $0 \%$ & $0 \%$ \\
\hline $2(1978)$ & Negative & $0 \%$ & $0 \%$ & $0 \%$ & $0 \%$ & $0.1 \%-1 \%$ & $0 \%$ & $0 \%$ & $0 \%$ \\
\hline $3(1978)$ & Positive & $0 \%$ & $0 \%$ & $0 \%$ & $0 \%$ & Het met & $0 \%$ & $0 \%$ & $0 \%$ \\
\hline $4(1978)$ & Negative & $0 \%$ & $0 \%$ & $0 \%$ & $0 \%$ & $1 \%-10 \%$ & $2.4 \%$ & $9.5 \%$ & $30.8 \%$ \\
\hline 5 (1978) & Positive & $0 \%$ & $0 \%$ & $0 \%$ & $0 \%$ & $10 \%-100 \%$ & $14.4 \%$ & $20.3 \%$ & $28.7 \%$ \\
\hline 6 (1978) & Negative & $0 \%$ & $0 \%$ & $0 \%$ & $0 \%$ & $0.1 \%-1 \%$ & $0.1 \%$ & $0.3 \%$ & $0.4 \%$ \\
\hline 7 (1978) & Negative & $0 \%$ & $0 \%$ & $0 \%$ & $0 \%$ & $0 \%$ & $0 \%$ & $0 \%$ & $0 \%$ \\
\hline 8 (1978) & No data & $10 \%-100 \%$ & $20.3 \%$ & $25.0 \%$ & $28.7 \%$ & $10 \%-100 \%$ & $57.4 \%$ & $61.6 \%$ & $75.8 \%$ \\
\hline 9 (1983) & Negative & $1 \%-10 \%$ & $0.7 \%$ & $1.9 \%$ & $5.4 \%$ & Failed ampl & $4.1 \%$ & $5.8 \%$ & $7.2 \%$ \\
\hline $10(1983)$ & Positive & $0 \%$ & $0 \%$ & $0 \%$ & $0 \%$ & $10 \%-100 \%$ & $21.8 \%$ & $26.8 \%$ & $33.0 \%$ \\
\hline I I (1983) & Negative & $0.1 \%-1 \%$ & $1.7 \%$ & $2.4 \%$ & $3.3 \%$ & Het met & $0 \%$ & $0 \%$ & $0 \%$ \\
\hline 12 (1983) & Positive & $0 \%$ & $0 \%$ & $0 \%$ & $0 \%$ & $1 \%-10 \%$ & $18.9 \%$ & $33.0 \%$ & $53.6 \%$ \\
\hline 13 (1983) & Negative & $1 \%-10 \%$ & $19.0 \%$ & $27.0 \%$ & $30.8 \%$ & $0 \%$ & $0 \%$ & $0 \%$ & $0 \%$ \\
\hline 14 (1983) & Negative & $0.1 \%-1 \%$ & $0.8 \%$ & $2.5 \%$ & $6.3 \%$ & Het met & $0.2 \%$ & $0.4 \%$ & $1.4 \%$ \\
\hline 15 (1983) & Negative & $0 \%$ & $0 \%$ & $0 \%$ & $0 \%$ & $0.1 \%-1 \%$ & $0.3 \%$ & $0.9 \%$ & $5.1 \%$ \\
\hline 16 (1988) & Negative & $0 \%$ & $0 \%$ & $0 \%$ & $0 \%$ & Het met & $0.4 \%$ & $0.8 \%$ & $1.3 \%$ \\
\hline 17 (1988) & Negative & $0 \%$ & $0 \%$ & $0 \%$ & $0 \%$ & $10 \%-100 \%$ & $93.3 \%$ & $1 \mid 4.9 \%$ & $186.6 \%$ \\
\hline 18 (1988) & Negative & $0 \%$ & $0 \%$ & $0 \%$ & $0 \%$ & Failed ampl & $0 \%$ & $0 \%$ & $0 \%$ \\
\hline 19 (1988) & Negative & $1 \%-10 \%$ & $3.4 \%$ & $5.8 \%$ & $10.9 \%$ & Het met & $0.2 \%$ & $0.8 \%$ & $3.8 \%$ \\
\hline 20 (1988) & Negative & $10 \%-100 \%$ & $12.5 \%$ & $14.4 \%$ & $21.8 \%$ & $0 \%$ & $0 \%$ & $0 \%$ & $0 \%$ \\
\hline 21 (1988) & Positive & $0 \%$ & $0 \%$ & $0 \%$ & $0 \%$ & Het met & $0.1 \%$ & $0.5 \%$ & $2.4 \%$ \\
\hline 22 (1988) & Positive & $0 \%$ & $0 \%$ & $0 \%$ & $0 \%$ & Het met & $2.2 \%$ & $2.7 \%$ & $3.8 \%$ \\
\hline 23 (1988) & Negative & $10 \%-100 \%$ & $18.9 \%$ & $20.3 \%$ & $21.7 \%$ & $0 \%$ & $0 \%$ & $0 \%$ & $0 \%$ \\
\hline 24 (1988) & Negative & $10 \%-100 \%$ & $9.5 \%$ & $14.4 \%$ & $15.4 \%$ & Het met & $0.1 \%$ & $0.2 \%$ & $0.7 \%$ \\
\hline 25 (1988) & Negative & $10 \%-100 \%$ & $6.3 \%$ & $7.7 \%$ & $10.9 \%$ & $0 \%$ & $0 \%$ & $0 \%$ & $0 \%$ \\
\hline 26 (1988) & Negative & $0 \%$ & $0 \%$ & $0 \%$ & $0 \%$ & Het met & $0.2 \%$ & $0.3 \%$ & $0.6 \%$ \\
\hline 27 (1988) & Negative & $10 \%-100 \%$ & $12.5 \%$ & $14.4 \%$ & $15.4 \%$ & Failed ampl & $0 \%$ & $0 \%$ & $0 \%$ \\
\hline $28(1988)$ & Positive & $0 \%$ & $0 \%$ & $0 \%$ & $0 \%$ & $0 \%$ & $0 \%$ & $0 \%$ & $0 \%$ \\
\hline 29 (1993) & Negative & $1 \%-10 \%$ & $3.6 \%$ & $5.8 \%$ & $7.7 \%$ & $0 \%$ & $0 \%$ & $0 \%$ & $0 \%$ \\
\hline 30 (1993) & Positive & $0 \%$ & $0 \%$ & $0 \%$ & $0 \%$ & $1 \%-10 \%$ & $2.9 \%$ & $8.8 \%$ & $14.4 \%$ \\
\hline 31 (1993) & Negative & $0 \%$ & $0 \%$ & $0 \%$ & $0 \%$ & Het met & $0.3 \%$ & $0.7 \%$ & $1.4 \%$ \\
\hline 32 (1993) & Negative & $10 \%-100 \%$ & $21.8 \%$ & $26.8 \%$ & $30.8 \%$ & $0.1 \%-1 \%$ & $0.1 \%$ & $0.3 \%$ & $0.7 \%$ \\
\hline 33 (1993) & Negative & $0 \%$ & $0 \%$ & $0 \%$ & $0 \%$ & $0 \%$ & $0 \%$ & $0 \%$ & $0 \%$ \\
\hline 34 (1993) & Negative & $10 \%-100 \%$ & $25.0 \%$ & $40.6 \%$ & $61.6 \%$ & $1 \%-10 \%$ & $2.9 \%$ & $5.4 \%$ & $8.8 \%$ \\
\hline 35 (1993) & Positive & $0 \%$ & $0 \%$ & $0 \%$ & $0 \%$ & Het met & $0.3 \%$ & $0.6 \%$ & $0.8 \%$ \\
\hline 36 (1993) & Negative & $10 \%-100 \%$ & $5.1 \%$ & $10.9 \%$ & $17.7 \%$ & $0.1 \%-1 \%$ & $0.2 \%$ & $0.6 \%$ & $1.4 \%$ \\
\hline 37 (1993) & Positive & $0 \%$ & $0 \%$ & $0 \%$ & $0 \%$ & $1 \%-10 \%$ & $23.3 \%$ & $25.0 \%$ & $28.7 \%$ \\
\hline 38 (1993) & Positive & $0 \%$ & $0 \%$ & $0 \%$ & $0 \%$ & $0 \%$ & $0 \%$ & $0 \%$ & $0 \%$ \\
\hline 39 (1998) & Negative & $0.1 \%-1 \%$ & $0 \%$ & $0 \%$ & $0 \%$ & $0 \%$ & $2.5 \%$ & $2.9 \%$ & $3.4 \%$ \\
\hline 40 (1998) & Negative & $0.1 \%-1 \%$ & $0.1 \%$ & $0.1 \%$ & $0.2 \%$ & Het met & $0.6 \%$ & $1.5 \%$ & $3.1 \%$ \\
\hline 41 (1998) & Negative & $10 \%-100 \%$ & $19.0 \%$ & $23.3 \%$ & $28.7 \%$ & $0 \%$ & $0 \%$ & $0 \%$ & $0 \%$ \\
\hline 42 (1998) & Positive & $0 \%$ & $0.1 \%$ & $0.3 \%$ & $0.7 \%$ & Het met & $0.2 \%$ & $0.4 \%$ & $1.4 \%$ \\
\hline 43 (1998) & Positive & $0 \%$ & $0 \%$ & $0 \%$ & $0 \%$ & $0 \%$ & $0 \%$ & $0 \%$ & $0 \%$ \\
\hline 44 (1998) & Positive & $0.1 \%-1 \%$ & $0.1 \%$ & $0.2 \%$ & $0.4 \%$ & Het met & $2.9 \%$ & $3.6 \%$ & $5.4 \%$ \\
\hline 45 (1998) & Positive & $0 \%$ & $0 \%$ & $0 \%$ & $0 \%$ & $0.1 \%-1 \%$ & $0.2 \%$ & $0.7 \%$ & $2.9 \%$ \\
\hline 46 (1998) & Positive & $0 \%$ & $0 \%$ & $0 \%$ & $0 \%$ & $0.1 \%-1 \%$ & $0 \%$ & $0 \%$ & $0 \%$ \\
\hline 47 (1998) & Positive & $0 \%$ & $0 \%$ & $0 \%$ & $0 \%$ & $10-100 \%$ & $21.8 \%$ & $30.8 \%$ & $50.0 \%$ \\
\hline 48 (1998) & Positive & $0 \%$ & $0 \%$ & $0 \%$ & $0 \%$ & Failed ampl & $0 \%$ & $0 \%$ & $0 \%$ \\
\hline 49 (2003) & Positive & $0 \%$ & $0 \%$ & $0 \%$ & $0 \%$ & $0 \%$ & $0 \%$ & $0 \%$ & $0 \%$ \\
\hline $50(2003)$ & Positive & $0 \%$ & $0 \%$ & $0 \%$ & $0 \%$ & Het met & $0.5 \%$ & $1 \%$ & $2.1 \%$ \\
\hline $5 I(2003)$ & No data & $0 \%$ & $0 \%$ & $0 \%$ & $0 \%$ & $0 \%$ & $0 \%$ & $0 \%$ & $0 \%$ \\
\hline $52(2003)$ & Positive & $0.1 \%-1 \%$ & $0.4 \%$ & $0.6 \%$ & $1.0 \%$ & $1 \%-10 \%$ & $2.7 \%$ & $3.9 \%$ & $5.1 \%$ \\
\hline
\end{tabular}


Table 2: Methylation levels of the samples as estimated by MS-HRM and SMART-MSP. (Continued)

\begin{tabular}{|c|c|c|c|c|c|c|c|c|c|}
\hline $53(2003)$ & Negative & $10 \%-100 \%$ & $2.7 \%$ & $6.3 \%$ & $16.5 \%$ & $1 \%-10 \%$ & $4.1 \%$ & $10.2 \%$ & $26.8 \%$ \\
\hline $54(2003)$ & Negative & $0 \%$ & $0 \%$ & $0 \%$ & $0 \%$ & $0 \%$ & $0 \%$ & $0 \%$ & $0 \%$ \\
\hline
\end{tabular}

An average methylation estimate as well as the highest and lowest possible methylation estimates calculated from the Ct-values of the triplicates for the gene and the control is given for SMART-MSP.

Chi-squared test $(\mathrm{p}$-value $=0.001192))$. Two samples, for which the MS-HRM and SMART-MSP did not give the same methylation status, were omitted from the analysis.

\section{Variation amongst bisulfite modifications}

As the variation among bisulfite modifications previously has been thoroughly evaluated using various PCR-based methods for single locus methylation detection $[27,28]$, we bisulfite modified a subset of the samples a second time, and tested for CDKN2A methylation using MSHRM. Results obtained after the second bisulfite modification were identical to the results obtained by the first bisulfite modification.

\section{Discussion}

DNA derived from FFPE tissue represents a highly valuable source of material for retrospective studies. However,
DNA derived from FFPE tissue is often highly degraded, and for certain cancer types a limited amount of tumor tissue may be available. When studying DNA methylation changes by PCR-based methods, it is necessary to modify the DNA with sodium bisulfite for preservation of the DNA methylation information of the original template. This treatment may further damage the DNA. Also, it is likely that the DNA becomes even more fragmented with age of storage.

Here, we have evaluated whether we could use sodium bisulfite treated DNA derived from FFPE tissue from NSCLC patients dating five to 30 years back in time for DNA methylation analysis. Two methodologies, SMARTMSP and MS-HRM, were used to assess the methylation status of each of the 54 samples available for this study.

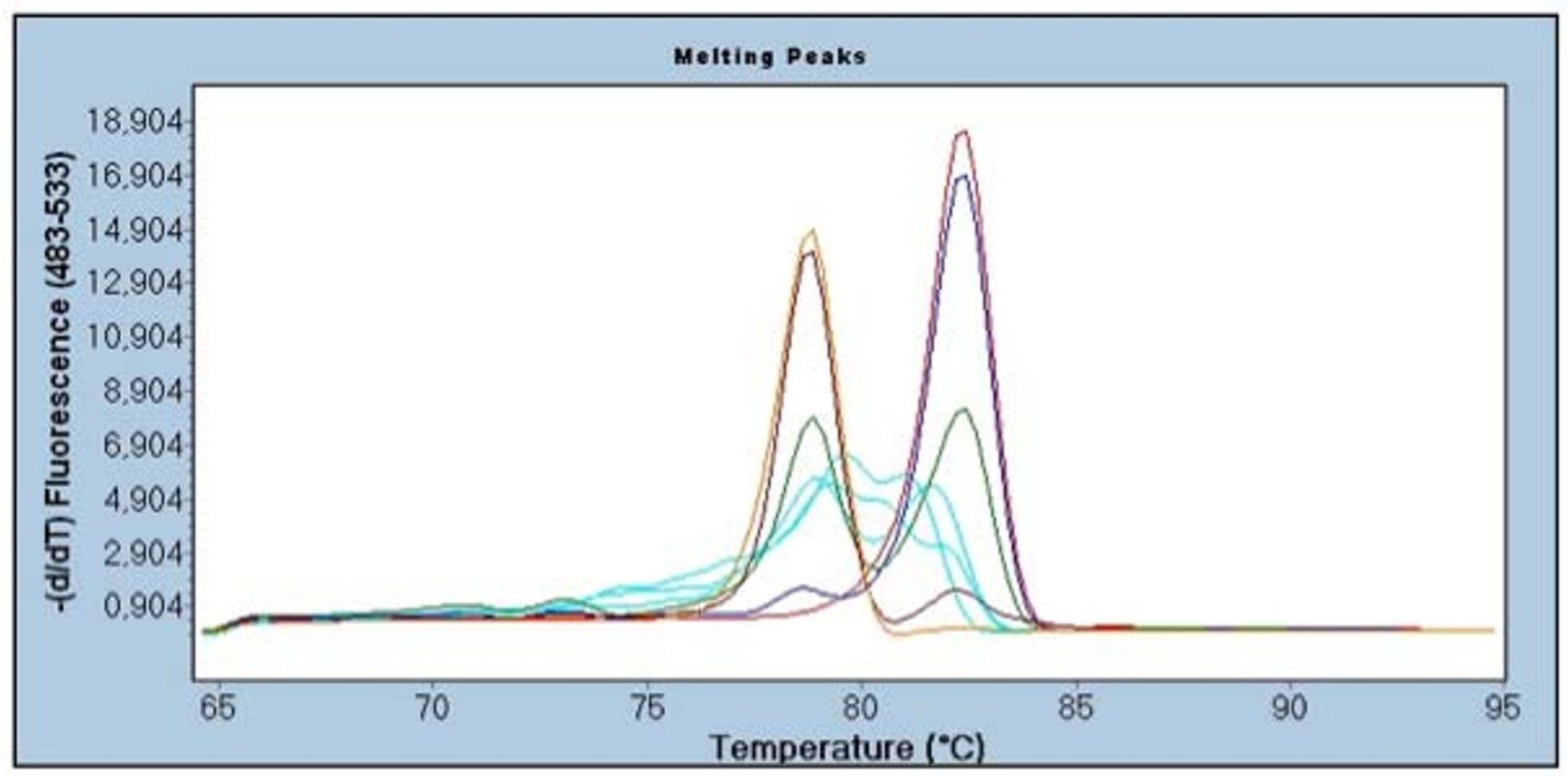

Figure 3

Melting profiles indicating that the DNA is heterogeneously methylated at the RARB promoter. If molecules, in which different $C_{P G}$ positions are methylated and unmethylated are amplified, the observed melting profile will be complex. These different molecules will form heteroduplexes and homoduplexes after the PCR and prior to the HRM step. The very early melting observed is likely to be the melting of various heteroduplexes. The intermediate and later melting are likely to be the melting of various homoduplexes with those having the highest number of CpG positions methylated melting the latest. The 100\% methylated standards are indicated in red, the 10\% methylated standards in blue, the $1 \%$ methylated standards in green, the $0.1 \%$ methylated standards in brown, the $0 \%$ methylated standard in orange and non template controls are indicated in black. A sample (in triplicate) judged to be heterogeneously methylated is indicated in turquoise. 


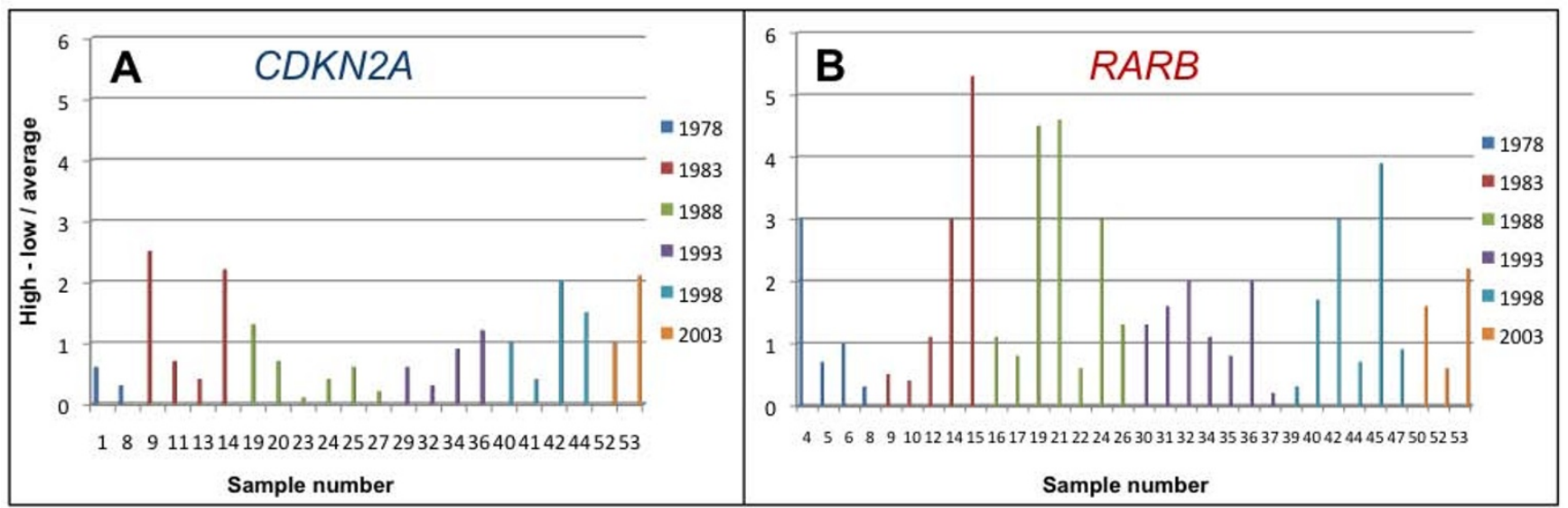

\section{Figure 4}

Reproducibility of the methylation estimates for the FFPE samples by SMART-MSP. Plots of the absolute difference between the highest and lowest possible methylation estimate divided by the average methylation estimate against the age of the samples for each gene are shown. A. The CDKN2A assay. $\mathbf{B}$. The RARB assay. It is observed that the overall reproducibility is better for the CDKN2A assay compared to the RARB assay. It can also be observed that the reproducibility did not depend on the age of the samples.

Both methods are highly sensitive and capable of measuring methylation levels.

Assays targeting the promoter $\mathrm{CpG}$ islands of the $C D K N 2 A$ and RARB genes were designed to evaluate the quality of the samples since aberrant methylation of these genes is implicated in NSCLC [29], and especially $C D K N 2 A$ has shown promising results as a biomarker for early detection [30].
The methylation status of all 54 samples could be determined for both genes using SMART-MSP, even in the oldest samples. When using MS-HRM, all samples could be scored for CDKN2A methylation, but five samples could not be scored for RARB methylation due to failed amplification in at least two of three replicates. This may be due to the fact that the MS-HRM RARB amplicon is almost twice as long as the SMART-MSP RARB amplicon (see Table 1). For all amplifiable samples a highly significant
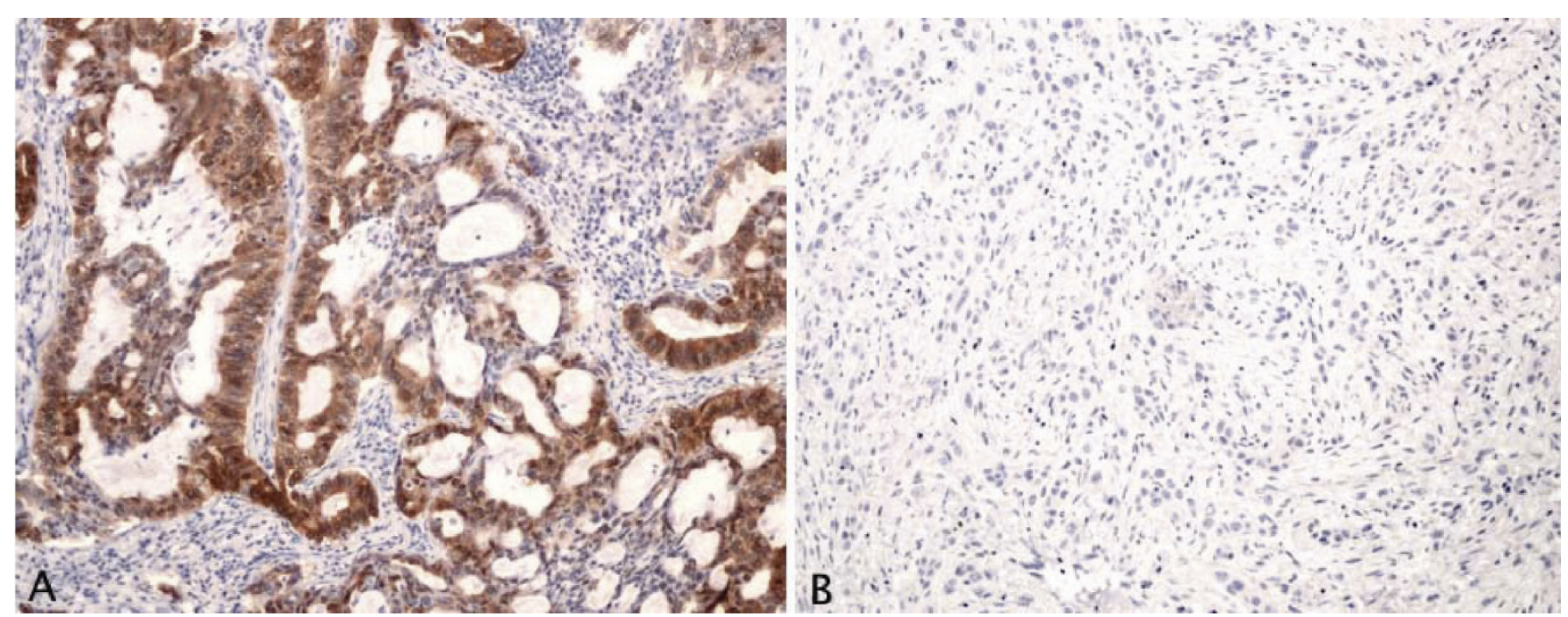

\section{Figure 5}

CDKN2A ( $p / 6)$ expression in NSCLC. A. A case in which immunohistochemical staining for pl6 showed positive nuclear and cytoplasmic staining $(\times 100)$. B. A case in which the invading tumor cells did not express $\mathrm{p} / 6(\times 100)$. 
correlation was observed between the methylation estimates provided by each method.

One sample was estimated to be methylated above $100 \%$ at the RARB promoter by SMART-MSP. Methylation estimates relative to in vitro methylated DNA may occasionally be obtained for heavily methylated genes because the calibrator (positive control) may not be 100\% methylated in spite of extensive SssI treatment [31].

We observed a tendency for the RARB promoter to be heterogeneously methylated. It was only possible to examine whether the DNA was heterogeneously methylated, when using MS-HRM as the SMART-MSP assays are designed only to amplify fully methylated molecules. The samples were scored as being heterogeneously methylated, when showing melting profiles characteristic for the amplification of molecules of different methylation content $[13,24]$.

The reproducibility of the SMART-MSP assays could be expected to be less satisfactory for the older samples. To investigate this hypothesis we plotted the absolute difference between the highest and lowest possible methylation estimate for the methylated samples divided by the average methylation estimate against the age of the samples for each gene. From these plots it was clear that the reproducibility did not decrease with the age of the samples (Figure 4). Therefore, we have, for the first time, showed the robustness of SMART-MSP and MS-HRM for methylation analysis of DNA extracted from FFPE tissue being up to 30 years old. The reproducibility was higher for the CDKN2A SMART-MSP assay compared to the RARB SMART-MSP assay. This may be explained by the tendency for the RARB promoter to be heterogeneously methylated in the samples we have tested.

Furthermore, we have evaluated whether immunohistochemical staining of the p16 protein correlated with methylation status of the CDKN2A (p16) gene. A highly significant correlation was found ( $p$-value $=0.001192)$, and all methylated samples except two, which were methylated at very low levels, were found to be negative. Twelve of 30 unmethylated samples were also negative by immunohistochemistry. This may be due to homozygous deletion of the CDKN2A ( $p 16)$ gene, which often is found in NSCLC [32].

A recent study has assessed the quality of archival FFPE tissue for DNA methylation studies using MS-HRM and MethyLight [27]. A high concordance between the MSHRM and MethyLight results was observed, and a high reproducibility in between different runs and bisulfite modifications was found. However, no information of the age of the FFPE tissue was provided.

The methylation assays we have developed analyze the same CpG positions in two different ways, using the same real-time PCR and HRM instrument. In spite of the innate differences of the two types of assays, we have shown that similar methylation estimates can be obtained. For this reason, a more accurate and reliable methylation estimate may be obtained when using both SMART-MSP and MSHRM.

\section{Conclusions}

In conclusion, DNA from FFPE tissue can be successfully used for methylation studies in spite of being 30 years old when using MS-HRM or SMART-MSP. These two methodologies are closed-tube, very sensitive, and require no fluorescent probes. Since MS-HRM and SMART-MSP can be performed on the same instrument, a more accurate methylation estimate can be achieved in the samples of interest, as each method verifies the results of the other.

\section{Competing interests}

The authors declare that they have no competing interests.

\section{Authors' contributions}

Conceived and designed the experiments: LSK, TKW, HH, and LLH. Performed the experiments: LSK, HH and BBT. Analyzed the data: LSK, TKW, BBT, CW, HH, and LLH. Contributed reagents/materials/analysis tools: LLH and HH. Wrote the paper: LSK, TKW, HH, and LLH. All authors have red and approved the final manuscript.

\section{Acknowledgements}

We acknowledge Michael Krypuy for critical reading of the manuscript. Roche Diagnostics, the Toyota, Lundbeck, and Augustinus Foundations funded this work.

\section{References}

I. Esteller M: Epigenetics in cancer. $N$ Engl J Med 2008, 358(I I): I | 48-II59.

2. Shi H, Wang MX, Caldwell CW: CpG islands: their potential as biomarkers for cancer. Expert Rev Mol Diagn 2007, 7(5):5 I9-53I.

3. Frommer M, McDonald LE, Millar DS, Collis CM, Watt F, Grigg GW, Molloy PL, Paul CL: A genomic sequencing protocol that yields a positive display of 5-methylcytosine residues in individual DNA strands. Proc Natl Acad Sci USA 1992, 89(5): |827- I83 I.

4. Kristensen LS, Hansen LL: PCR-Based Methods for Detecting Single-Locus DNA Methylation Biomarkers in Cancer Diagnostics, Prognostics, and Response to Treatment. Clin Chem 2009, 55(8): | 47|-83.

5. Herman JG, Graff JR, Myohanen S, Nelkin BD, Baylin SB: Methylation-specific PCR: a novel PCR assay for methylation status of CpG islands. Proc Natl Acad Sci USA 1 996, 93( I 8):982 I-9826.

6. Cameron EE, Baylin SB, Herman JG: pI5(INK4B) CpG island methylation in primary acute leukemia is heterogeneous and suggests density as a critical factor for transcriptional silencing. Blood 1999, 94(7):2445-245I.

7. Kristensen LS, Mikeska T, Krypuy M, Dobrovic A: Sensitive Melting Analysis after Real Time-Methylation Specific PCR (SMART- 
MSP): high-throughput and probe-free quantitative DNA methylation detection. Nucleic Acids Res 2008, 36(7):e42.

8. Rand K, Qu W, Ho T, Clark SJ, Molloy P: Conversion-specific detection of DNA methylation using real-time polymerase chain reaction (ConLight-MSP) to avoid false positives. Methods 2002, 27(2): I | 4-I20.

9. Shaw RJ, Akufo-Tetteh EK, Risk JM, Field JK, Liloglou T: Methylation enrichment pyrosequencing: combining the specificity of MSP with validation by pyrosequencing. Nucleic Acids Res 2006, 34(II):e78.

10. Eads CA, Danenberg KD, Kawakami K, Saltz LB, Blake C, Shibata D, Danenberg PV, Laird PW: MethyLight: a high-throughput assay to measure DNA methylation. Nucleic Acids Res 2000, 28(8):E32.

II. Colella S, Shen L, Baggerly KA, Issa JP, Krahe R: Sensitive and quantitative universal Pyrosequencing methylation analysis of CpG sites. Biotechniques 2003, 35(I): | 46-150.

12. Gonzalgo ML, Jones PA: Rapid quantitation of methylation differences at specific sites using methylation-sensitive single nucleotide primer extension (Ms-SNuPE). Nucleic Acids Res 1997, 25(I 2):2529-253I.

13. Worm J, Aggerholm A, Guldberg P: In-tube DNA methylation profiling by fluorescence melting curve analysis. Clin Chem 200I, 47(7): I I83-I I89.

14. Xiong Z, Laird PW: COBRA: a sensitive and quantitative DNA methylation assay. Nucleic Acids Res 1997, 25(I 2):2532-2534

15. Warnecke PM, Stirzaker C, Melki JR, Millar DS, Paul CL, Clark SJ: Detection and measurement of PCR bias in quantitative methylation analysis of bisulphite-treated DNA. Nucleic Acids Res 1997, 25(2I):4422-4426.

16. Wojdacz TK, Hansen LL: Reversal of PCR bias for improved sensitivity of the DNA methylation melting curve assay. Biotechniques 2006, 4 I(3):274. 276, 278.

17. Wittwer CT, Reed GH, Gundry CN, Vandersteen JG, Pryor RJ: High-resolution genotyping by amplicon melting analysis using LCGreen. Clin Chem 2003, 49(6 Pt I):853-860.

18. Wojdacz TK, Dobrovic A: Methylation-sensitive high resolution melting (MS-HRM): a new approach for sensitive and highthroughput assessment of methylation. Nucleic Acids Res 2007, 35(6): 41 .

19. Wojdacz TK, Dobrovic A, Hansen LL: Methylation-Sensitive High-Resolution Melting. Nature Protocols 2008, 3:1903-1908.

20. Wojdacz TK, Hansen LL, Dobrovic A: A new approach to primer design for the control of PCR bias in methylation studies. BMC Res Notes 2008, 1:54.

21. Hansen LL, Andersen J, Overgaard J, Kruse TA: Molecular genetic analysis of easily accessible breast tumour DNA, purified from tissue left over from hormone receptor measurement. APMIS 1998, 106(3):37I-377.

22. Gundersen HJ, Bagger P, Bendtsen TF, Evans SM, Korbo L, Marcussen N, Moller A, Nielsen K, Nyengaard JR, Pakkenberg B, et al.: The new stereological tools: disector, fractionator, nucleator and point sampled intercepts and their use in pathological research and diagnosis. APMIS 1988, 96(10):857-88I.

23. Weisenberger DJ, Campan M, Long TI, Kim M, Woods C, Fiala E, Ehrlich M, Laird PW: Analysis of repetitive element DNA methylation by MethyLight. Nucleic Acids Res 2005, 33(21):6823-6836.

24. Candiloro IL, Mikeska T, Hokland P, Dobrovic A: Rapid analysis of heterogeneously methylated DNA using digital methylationsensitive high resolution melting: application to the CDKN2B (p I5) gene. Epigenetics Chromatin 2008, I( I):7.

25. Livak KJ, Schmittgen TD: Analysis of relative gene expression data using real-time quantitative PCR and the 2(-Delta Delta C(T)) Method. Methods 200I, 25(4):402-408.

26. Feng Q, Hawes SE, Stern JE, Wiens L, Lu H, Dong ZM, Jordan CD Kiviat NB, Vesselle H: DNA methylation in tumor and matched normal tissues from non-small cell lung cancer patients. Cancer Epidemiol Biomarkers Prev 2008, I 7(3):645-654.

27. Balic M, Pichler M, Strutz J, Heitzer E, Ausch C, Samonigg H, Cote RJ, Dandachi $\mathrm{N}$ : High quality assessment of DNA methylation in archival tissues from colorectal cancer patients using quantitative high-resolution melting analysis. I Mol Diagn 2009, I I(2): $102-108$.

28. Ogino S, Kawasaki T, Brahmandam M, Cantor M, Kirkner GJ, Spiegelman D, Makrigiorgos GM, Weisenberger DJ, Laird PW, Loda M, et al: Precision and performance characteristics of bisulfite con- version and real-time PCR (MethyLight) for quantitative DNA methylation analysis. J Mol Diagn 2006, 8(2):209-217.

29. Anglim PP, Alonzo TA, Laird-Offringa IA: DNA methylation-based biomarkers for early detection of non-small cell lung cancer: an update. Mol Cancer 2008, 7(I):8I

30. Palmisano WA, Divine KK, Saccomanno G, Gilliland FD, Baylin SB Herman JG, Belinsky SA: Predicting lung cancer by detecting aberrant promoter methylation in sputum. Cancer Res 2000 , 60(2I):5954-5958.

3I. Tsou JA, Galler JS, Wali A, Ye W, Siegmund KD, Groshen S, Laird PW, Turla S, Koss MN, Pass HI, et al.: DNA methylation profile of 28 potential marker loci in malignant mesothelioma. Lung Cancer 2007, 58(2):220-230

32. Kraunz KS, Nelson HH, Lemos M, Godleski JJ, Wiencke JK, Kelsey KT: Homozygous deletion of p I6INK4a and tobacco carcinogen exposure in nonsmall cell lung cancer. Int J Cancer 2006, I I 8(6): $1364-1369$.

\section{Pre-publication history}

The pre-publication history for this paper can be accessed here:

http://www.biomedcentral.com/1471-2407/9/453/pre pub
Publish with Bio Med Central and every scientist can read your work free of charge

"BioMed Central will be the most significant development for disseminating the results of biomedical research in our lifetime. "

Sir Paul Nurse, Cancer Research UK

Your research papers will be:

- available free of charge to the entire biomedical community

- peer reviewed and published immediately upon acceptance

- cited in PubMed and archived on PubMed Central

- yours - you keep the copyright
BioMedcentral 